\title{
Mechanical State Model of Multispan Continuous Deep Beam under Concentrated Load
}

\author{
Chun-Liang Li and Dong-Miao Zhang \\ School of Communication Science \& Engineering, Jilin Jianzhu University, Changchun 130118, China \\ Correspondence should be addressed to Chun-Liang Li; lichli3300@163.com
}

Received 17 May 2013; Revised 9 November 2013; Accepted 9 November 2013

Academic Editor: Ashraf M. Zenkour

Copyright (c) 2013 C.-L. Li and D.-M. Zhang. This is an open access article distributed under the Creative Commons Attribution License, which permits unrestricted use, distribution, and reproduction in any medium, provided the original work is properly cited.

\begin{abstract}
In the present study, the mechanical model of the multispan continuous deep beam under concentrated load was established on the state space theory, and with the model, the two-span continuous deep beam was calculated. And the calculation results are consistent with ANSYS results, which show that the model without the plane section assumption is accurate and applicable. The changes of the deflection and the section strain along the beam height were analyzed with the beam height variation. The results showed that the normal stress and the shear stress coexisted in the cross-section of multi-span continuous deep beam, which means that the shear stress can cause the cross section warping, while the normal stress can result in the section in parallel with the neutral layer extrusion. In addition, we incidentally found that, with the increase of the beam height, the impact of the buckling deformation and the extrusion deformation impact on the beam bending increase gradually. A new design method, which has been provided by the established mechanical model of the multi-span continuous deep beam, has extended the space of the calculation method on traditional continuous deep beam.
\end{abstract}

\section{Introduction}

The multispan continuous deep beam is mainly used to bear the vertical load, and there are the normal stress and the shear stress in the cross-section of the structure when the deep beam bears concentrated load, while the shear stress can lead to the cross-section warping and the normal stress can lead to extrusion in the section in parallel with the neutral layer [1]. With the increase of the beam height, the shear deformation and the extrusion deformation increasingly impact on the beam bending, but the influence of the extrusion deformation is far less than that of the shear deformation.

Timoshenko theory also adopted the plane section assumption to study the transverse shear deformation of the deep beam, and in terms of the two factors of shear deformation and rotary inertia of the structure, it pointed out that the rotation of the cross-section was caused by the bending and the transverse shear deformation. This method neither can calculate the exact shearing strain nor satisfy the nonshear boundary conditions on the top and bottom surface, at the same time [2-4].
Levinson [5, 6] put forward the higher-order shear deformation theory without the plane section assumption. It satisfied the nonshear boundary conditions on the upper and bottom surface. But the model was not from variational principle because the governing differential equations were established with the section equilibrium condition of the beam.

Gao Wang [7] exploited the general solution of Papkovich-Neuber and the Lure operator to get directly various one-dimensional equations, which constitute the refined theory of symmetry deformation beam.

Meanwhile, the finite element method, the finite integration method, and the series method were also brought in the field of mechanics about the deep beam [8-12]. The transverse bending stress of the deep beam under uniform load had been widely studied in the literature [13]. The mechanical characteristics of the deep beam under concentrated load also had been studied in the condition of large deformation [14]. The elastic plane problems had been solved by the sum function method, and the stress state of the simply supported deep beam had been analyzed under triangular load. At the same time, the Fourier series solutions were 


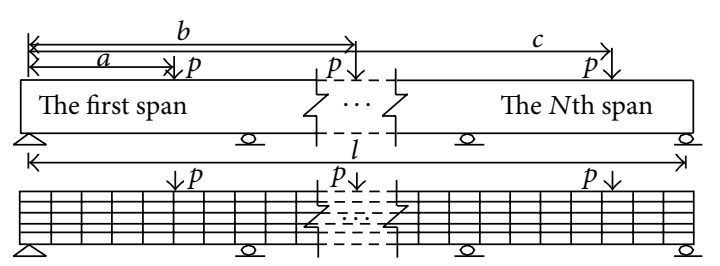

FIGURE 1: Mesh generation of the multispan continuous deep beam.

presented in the literature [15]. The aforementioned theories had considered the influence of the shear deformation and the extrusion deformation on the deep beam, but they all made different assumptions to study the distribution of two kinds of deformation.

In order to get more accurate calculation, we could not adopt the plane section assumption and the longitudinal fibers nonextrusion assumption to study the deformation of the multispan continuous deep beam under concentrated load [16], because the distribution of internal force is complicated gradually with the increase of the degree of statical indeterminacy, especially in multispan continuous deep beams.

According to the literature, so far, there are few studies about the multispan continuous deep beam under concentrated load; in addition, there is no explanation about the design of the multispan continuous deep beam under concentrated load in the current Concrete Structure Design Code, even not many studies on the stress distribution law. That is to say there is no feasible and reasonable calculation method on the structure, so it has practical significance to study the mechanical characteristics and calculation method of the multispan continuous deep beam under concentrated load, and also it has theoretical value to master the stress distribution law of the deep beam.

This study analyzed the multispan continuous deep beam under concentrated load without the plane section assumption and consequently decreased the multivariate calculation scale effectively; it will open up a new way to the multispan continuous deep beam study area.

\section{Mechanics Equation of the Multispan Continuous Deep Beam under the Concentrated Load}

2.1. Mesh Generation of the Multispan Continuous Deep Beam. In terms of high deep beam and the large shear stress in the cross-section of the deep beam, the multispan continuous deep beam was divided into some thin storey beams according to the material composition and the calculation accuracy as shown in Figure 1.

2.2. Mechanics Resolution and Treatment Method on the Middle Supports. The multispan continuous deep beam was divided into some thin storey beams according to the conditions of the displacement continuity and the stress equilibrium between the adjacent interfaces of the structural layers. Then the middle supports of the deep beam were

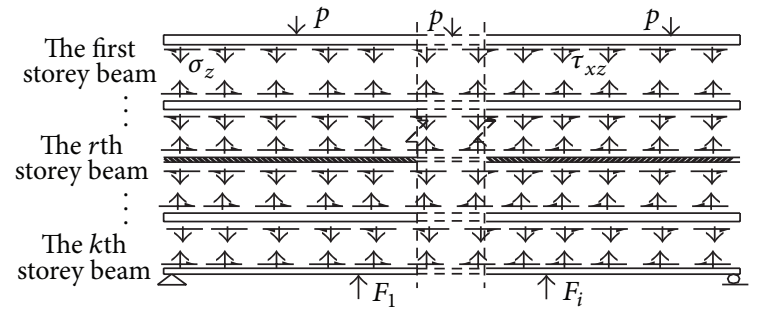

FIGURE 2: Forced state of disassembled beam.

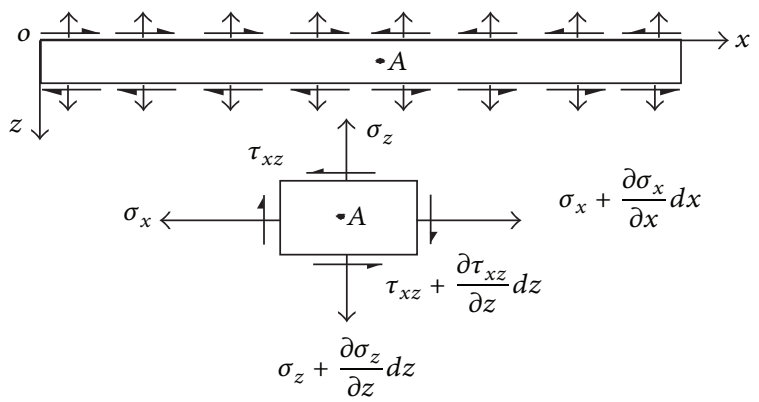

FIGURE 3: Forced state diagram of the $r$ th storey beam.

removed, and the equivalent vertical forces were applied on the locations of the middle supports to make sure the locations of the middle supports have no vertical movement as shown in Figure 2.

2.3. State Model Establishment of Each Storey Beam. Taking any storey beam $r$ from the first storey to the $k$ th storey, we established a local coordinate system to study the stress state of any point $A(x, z)$ in the $r$ th storey beam as shown in Figure 3.

(1) Balance equation of the $r$ th storey beam:

$$
\begin{aligned}
& \frac{\partial \sigma_{x}}{\partial x}+\frac{\partial \tau_{x z}}{\partial z}=0 \\
& \frac{\partial \tau_{x z}}{\partial x}+\frac{\partial \sigma_{z}}{\partial z}=0
\end{aligned}
$$

(2) Physical equation of the $r$ th storey beam:

$$
\begin{gathered}
\varepsilon_{x}=\frac{1}{E_{x}}\left(\sigma_{x}-\mu \cdot \sigma_{z}\right), \\
\varepsilon_{z}=\frac{1}{E_{z}}\left(\sigma_{z}-\mu \cdot \sigma_{x}\right), \\
\gamma_{x z}=\frac{1}{G}\left(\tau_{x z}\right) .
\end{gathered}
$$


(3) Geometric equation of the $r$ th storey beam:

$$
\begin{gathered}
\varepsilon_{x}=\frac{\partial u}{\partial x} \\
\varepsilon_{z}=\frac{\partial w}{\partial z} \\
\gamma_{x z}=\frac{\partial u}{\partial z}+\frac{\partial w}{\partial x},
\end{gathered}
$$

where $u$ and $w$ are the displacement of a certain point along the direction of $x$ and $z$ in the beam.

(4) State equation establishment of the $r$ th storey beam.

We establish the first derivative state equation of about $Z$ direction with (1), (2), and (3):

$$
\left\{\begin{array}{l}
\frac{\partial u}{\partial z} \\
\frac{\partial \sigma_{z}}{\partial z} \\
\frac{\partial w}{\partial z} \\
\frac{\partial \tau_{x z}}{\partial z}
\end{array}\right\}=\left[\begin{array}{cccc}
0 & 0 & -\frac{\partial}{\partial x} & \frac{1}{G} \\
0 & 0 & 0 & -\frac{\partial}{\partial x} \\
-\mu \frac{\partial}{\partial x} \cdot \frac{E_{x}}{E_{z}} & \frac{1-\mu^{2}}{E_{z}} & 0 & 0 \\
-E_{x} \frac{\partial^{2}}{\partial x^{2}} & -\mu \frac{\partial}{\partial x} & 0 & 0
\end{array}\right] \cdot\left[\begin{array}{c}
u \\
\sigma_{z} \\
w \\
\tau_{x z}
\end{array}\right]
$$

(5) Introduction of Fourier series.

Suppose

$$
\left\{\begin{array}{c}
u \\
\sigma_{z} \\
w \\
\tau_{x z}
\end{array}\right\}=\left\{\begin{array}{l}
\sum_{n} U_{n}(z) \cdot \cos \left(\frac{n \pi x}{l}\right) \\
\sum_{n} \sigma_{n}(z) \cdot \sin \left(\frac{n \pi x}{l}\right) \\
\sum_{n} W_{n}(z) \cdot \sin \left(\frac{n \pi x}{l}\right) \\
\sum_{n} \tau_{n}(z) \cdot \cos \left(\frac{n \pi x}{l}\right)
\end{array}\right\},
$$

where $U_{n}(z), W_{n}(z), \sigma_{n}(z)$, and $\tau_{n}(z)$ are the components of the displacement and the stress.

From (6) and (5), we can get the state variable $\sigma_{x}$

$$
\begin{aligned}
\sigma_{x}= & E_{x} \cdot \sum_{n} U_{n}(z) \cdot \sin \left(\frac{n \pi x}{l}\right) \cdot\left(-\frac{n \pi}{l}\right) \\
& +\mu \cdot \sum_{n} \sigma_{n}(z) \cdot \sin \left(\frac{n \pi x}{l}\right) .
\end{aligned}
$$

It is obvious that (5) and (6) all meet the boundary condition, $\sigma_{x}(0, z)=0, \sigma_{x}(l, z)=0, w(0, z)=0$, and $w(l, z)=0$.
(6) Solution of state equation of the $r$ th storey beam. To put (6) into (4), we can get the following:

$$
\begin{aligned}
& \frac{\partial}{\partial z}\left\{\begin{array}{c}
U_{n}(z) \\
\sigma_{n}(z) \\
W_{n}(z) \\
\tau_{n}(z)
\end{array}\right\}=\left[\begin{array}{cccc}
0 & 0 & -\frac{n \pi}{l} & \frac{1}{G} \\
0 & 0 & 0 & \frac{n \pi}{l} \\
\frac{n \pi \mu}{l} \cdot \frac{E_{x}}{E_{z}} & \frac{1-\mu^{2}}{E_{z}} & 0 & 0 \\
\frac{E_{x} \cdot n^{2} \pi^{2}}{l^{2}} & -\frac{n \pi \mu}{l} & 0 & 0
\end{array}\right] \\
& \cdot\left[\begin{array}{c}
U_{n}(z) \\
\sigma_{n}(z) \\
W_{n}(z) \\
\tau_{n}(z)
\end{array}\right] .
\end{aligned}
$$

It is obvious that the coefficient matrix in (8) has been translated into the constant coefficient matrix; suppose

$$
K_{n}=\left[\begin{array}{cccc}
0 & 0 & -\frac{n \pi}{l} & \frac{1}{G} \\
0 & 0 & 0 & \frac{n \pi}{l} \\
\frac{n \pi \mu}{l} \cdot \frac{E_{x}}{E_{z}} & \frac{1-\mu^{2}}{E_{z}} & 0 & 0 \\
\frac{E_{x} \cdot n^{2} \pi^{2}}{l^{2}} & -\frac{n \pi \mu}{l} & 0 & 0
\end{array}\right] .
$$

Then (8) is simplified into

$$
\left\{\begin{array}{c}
U_{n}(z) \\
\sigma_{n}(z) \\
W_{n}(z) \\
\tau_{n}(z)
\end{array}\right\}=\left\{K_{n}\right\} \cdot\left[\begin{array}{c}
U_{n}(z) \\
\sigma_{n}(z) \\
W_{n}(z) \\
\tau_{n}(z)
\end{array}\right] .
$$

According to matrix exponent method, the solution of (10) is obtained

$$
\left\{\begin{array}{c}
U_{n}(z) \\
\sigma_{n}(z) \\
W_{n}(z) \\
\tau_{n}(z)
\end{array}\right\}=e^{\left\{K_{n}\right\} \cdot z} \cdot\left[\begin{array}{c}
U_{n}(0) \\
\sigma_{n}(0) \\
W_{n}(0) \\
\tau_{n}(0)
\end{array}\right]
$$

Suppose

$$
\begin{gathered}
R_{n}(z)=\left[U_{n}(z), \sigma_{n}(z), W_{n}(z), \tau_{n}(z)\right]^{T}, \\
D_{n}(z)=e^{\left\{K_{n}\right\} \cdot z}, \\
R_{n}(0)=\left[U_{n}(0), \sigma_{n}(0), W_{n}(0), \tau_{n}(0)\right]^{T} .
\end{gathered}
$$

Then (11) is simplified into

$$
R_{n}(z)=D_{n}(z) \cdot R_{n}(0) .
$$


When $z=h_{r}$, (13) is transformed into

$$
R_{n}\left(h_{r}\right)=D_{n}\left(h_{r}\right) \cdot R_{n}\left(0_{r}\right),
$$

where $0_{r}\left(0_{r}=0\right)$ is the coordinate value of the $r$ th storey beam top, $h_{r}$ is the coordinate value of the $r$ th storey beam bottom ( $h_{r}$ is equal to $r$ th storey's beam total height), $R_{n}\left(0_{r}\right)$ is the column vector of the displacement and the stress components at the location of $z=0_{r}$, and $R_{n}\left(h_{r}\right)$ is the column vector of the displacement and the stress components at the location of $z=h_{r}$.

2.4. State Equation Combination. We can link up all the storey beams according to the conditions of the displacement continuity and the stress equilibrium between the adjacent interfaces of the structural layers by (14), and when $r=$ $1 \cdots r \cdots K$, we can get

The frist storey beam : $R_{n}\left(h_{1}\right)=D_{n}\left(h_{1}\right) \cdot R_{n}\left(0_{1}\right)$,

The $r$ th storey beam : $R_{n}\left(h_{r}\right)=D_{n}\left(h_{r}\right) \cdot R_{n}\left(0_{r}\right)$,

The $k$ th storey beam : $R_{n}\left(h_{K}\right)=D_{n}\left(h_{K}\right) \cdot R_{n}\left(0_{K}\right)$,

$$
R_{n}\left(h_{r}\right)=R_{n}\left(0_{r+1}\right) .
$$

From (15), we link up each storey beam from top to bottom: The frist layer : $R_{n}\left(h_{1}\right)=D_{n}\left(h_{1}\right) \cdot R_{n}\left(0_{1}\right)$,

The frist layer to the $r$ th layer :

$$
R_{n}\left(h_{r}\right)=D_{n}\left(h_{r}\right) \cdots D_{n}\left(0_{2}\right) \cdot D_{n}\left(0_{1}\right) \cdot R_{n}\left(0_{1}\right),
$$

The frist layer to the $k$ th layer :

$$
\begin{aligned}
R_{n} & \left(h_{K}\right) \\
\quad & =D_{n}\left(h_{K}\right) \cdot D_{n}\left(h_{K-1}\right) \cdots D_{n}\left(0_{2}\right) \cdot D_{n}\left(0_{1}\right) \cdot R_{n}\left(0_{1}\right) .
\end{aligned}
$$

The last row in (16) is the state equation of the whole composite structure.

Suppose, $\prod_{i=K}^{1} D_{n}\left(h_{i}\right)=D_{n}\left(h_{K}\right) \cdot D_{n}\left(h_{K-1}\right) \cdots D_{n}\left(0_{2}\right)$. $D_{n}\left(0_{1}\right)$; then the state model of the whole structure can be written as

$$
R_{n}\left(h_{K}\right)=\prod_{i=K}^{1} D_{n}\left(h_{i}\right) \cdot R_{n}\left(0_{1}\right) .
$$

\subsection{Discussion of Model Equation's Solvability}

(1) Known Quantity and Unknown Quantity in State Components. Equation (17) can be rewritten as
The coefficient matrices in (18) are all constant matrices, and the unknown quantities $\left[\begin{array}{llll}U_{n}\left(h_{K}\right) & \sigma_{n}\left(h_{K}\right) & W_{n}\left(h_{K}\right) & \tau_{n}\left(h_{K}\right)\end{array}\right]^{T}$ and $\left[\begin{array}{llll}U_{n}(0) & \sigma_{n}(0) & W_{n}(0) & \tau_{n}(0)\end{array}\right]$ are the stress and displacement component value on the top and bottom of the deep beam.

(2) Boundary Condition. We take the two-span continuous deep beam; for example, we establish the load boundary conditions of the top and bottom beam in Figure 1.

The boundary condition of the deep beam's top surface is

$$
\begin{gathered}
p(x)=\sigma_{z}(x, 0) \\
\tau_{x z}(x, 0)=0
\end{gathered}
$$

where $p(x)$ is the concentrated load on the deep beam's top surface.

The boundary condition of the deep beam's bottom surface is

$$
\begin{gathered}
F(x)=\sigma_{z}\left(x, h_{K}\right) \\
\tau_{x z}\left(x, h_{K}\right)=0,
\end{gathered}
$$

where $F(x)$ is the support force of each middle support.

The deflection of the $j$ th middle support of the continuous beam meets

$$
w\left(x_{j}, h_{K}\right)=0,
$$


where $x_{j}$ is the $x$ direction coordinate of the $j$ th middle support, $j=1 \rightarrow m$, and

$$
w\left(x_{j}, h_{K}\right)=\sum_{n} W_{n}\left(h_{K}\right) \cdot \sin \left(\frac{n \pi x_{j}}{l}\right) .
$$

The concentrated force $p(x)$ on the top surface of the beam can be expanded into the form of Fourier series

$$
p(x)=\sum_{n}\left\{\frac{2 p}{l} \cdot\left[\sum_{u} \sin \left(\frac{n \pi x_{i}}{l}\right)\right] \cdot \sin \left(\frac{n \pi x}{l}\right)\right\},
$$

where $x_{i}$ is the $x$ direction coordinate of the $i$ th concentrated force on the top surface of the beam, and $i=1 \rightarrow u$.

(3) Solution of Unknown Quantity in State Component. According to the aforementioned boundary conditions above and the Fourier series expansion of the mechanical quantities, we can solve the expressions for the stress components $\left[\sigma_{n}(0), \tau_{n}(0), \sigma_{n}\left(h_{k}\right), \tau_{n}\left(h_{k}\right)\right]$, and the concrete solving process as follows:

$$
\begin{aligned}
\sigma_{z}(x, 0)= & p(x) \Longrightarrow \sum_{n} \sigma_{n}(0) \cdot \sin \left(\frac{n \pi x}{l}\right) \\
= & \sum_{n}\left\{\frac{2 p}{l} \cdot\left[\sum_{u} \sin \left(\frac{n \pi x_{i}}{l}\right)\right]\right. \\
& \left.\cdot \sin \left(\frac{n \pi x}{l}\right)\right\} \Longrightarrow \sigma_{n}(0) \\
= & \frac{2 p}{l} \cdot\left[\sum_{u} \sin \left(\frac{n \pi x_{i}}{l}\right)\right], \\
\tau_{x z}(x, 0)=0= & \sum_{n} \tau_{n}(0) \cdot \cos \left(\frac{n \pi x}{l}\right) \Longrightarrow \tau_{n}(0)=0, \\
\sigma_{z}\left(x, h_{K}\right)= & F(x)=\sum_{n} \sigma_{n}\left(h_{K}\right) \cdot \sin \left(\frac{n \pi x}{l}\right), \\
\tau_{x z}\left(x, h_{K}\right)=0= & \sum_{n} \tau_{n}\left(h_{K}\right) \cdot \cos \left(\frac{n \pi x}{l}\right) \Longrightarrow \tau_{n}\left(h_{K}\right)=0 .
\end{aligned}
$$

The deflection of the $j$ th middle support

$$
w\left(x_{j}, h\right)=0=\sum_{n} W_{n}\left(h_{K}\right) \cdot \sin \left(\frac{n \pi x_{j}}{l}\right) \Longrightarrow W_{n}\left(h_{K}\right)=0 .
$$

Only $\sigma_{n}\left(h_{K}\right)$ is the unknown variable in the stress components $\left[\sigma_{n}(0), \tau_{n}(0), \sigma_{n}\left(h_{k}\right), \tau_{n}\left(h_{k}\right)\right]$, but $\sigma_{n}\left(h_{K}\right)$ can be solved according to zero deflection on the bottom surface of the middle support. So the stress components $\left[\sigma_{n}(0), \tau_{n}(0), \sigma_{n}\left(h_{k}\right), \tau_{n}\left(h_{k}\right)\right]$ are all known variables, and the other two components $\left[U_{n}(0), W_{n}(0)\right]$ can also be solved with (18). So the stress components $R_{n}(0)=$ $\left[U_{n}(0), \sigma_{n}(0), W_{n}(0), \tau_{n}(0)\right]$ of the deep beam's top surface are all solved. The displacement and the stress component value of the continuous deep beam can be all solved with (18), and putting the solved components into the Fourier series expressions of the displacement and the stress, so the mechanical parameters of the multispan continuous deep beam can be also solved.

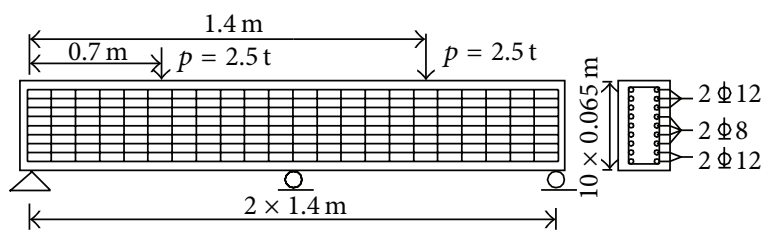

FIgURE 4: Schematic diagram of the beam.

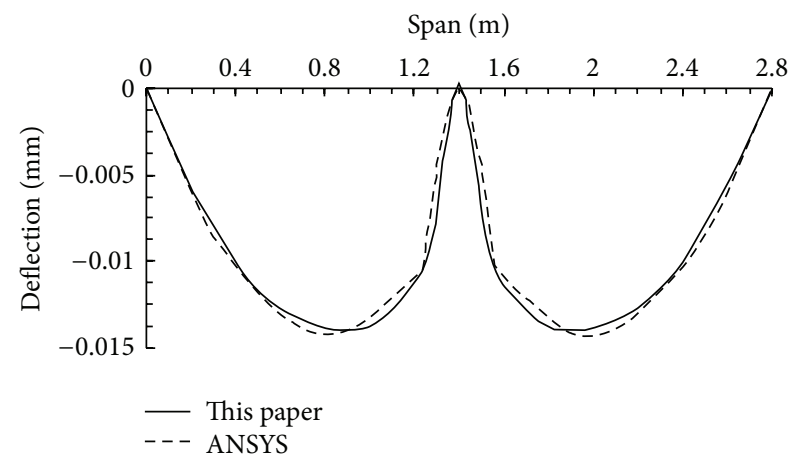

Figure 5: The deflection curve of the bottom of the two-span continuous deep beam.

\section{Example}

3.1. Example Introduction. The beam height is $0.65 \mathrm{~m}$, the concrete strength is $\mathrm{C} 40$, the beam length is $3.00 \mathrm{~m}$, the computational span of the single span is $1.40 \mathrm{~m}$, the beam width is $0.12 \mathrm{~m}$, the steel bar diameters are $\Phi 12$ and $\Phi 8$, respectively, and the load $P$ on the deep beam's top is $2.5 \mathrm{t}$ (Figure 4).

3.2. Comparison and Discussion. In order to test the accuracy of the theoretical model, we compared the theoretical model results with ANSYS.

(1) Deflection Curves. Figure 5 shows the deflection curves of the two-span continuous deep beam. The calculation results of the theoretical model are consistent with those of ANSYS, and the two curves overlapped together, which can prove the validity and applicability of this established model and also suggest that the established mechanical model can be used to analyze the mechanical behavior of the multispan continuous deep beam.

(2) Shear Stress Distribution Curves along the Beam Height. Figure 6(b) shows the shear stress distribution along the beam height (as Figure 6(a) shows the location of the observed cross-sections). It is quite obvious that the theoretical results are consistent with ANSYS results, and there is no shear stress on the top and bottom surface of the structure, which is consistent with the fact.

(3) Transverse Strain Distribution Curves along the Beam Height. Figure 7 shows the transverse strain distribution along the beam height (as Figure 6(a) shows the location of the observed cross-sections). The agreement is good in Figure 7, 


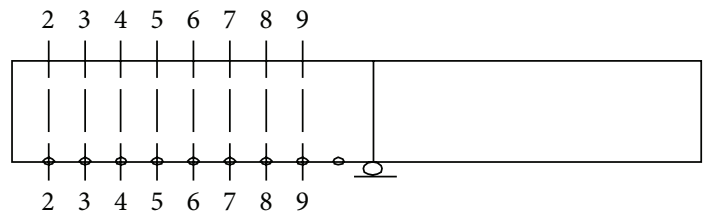

(a)

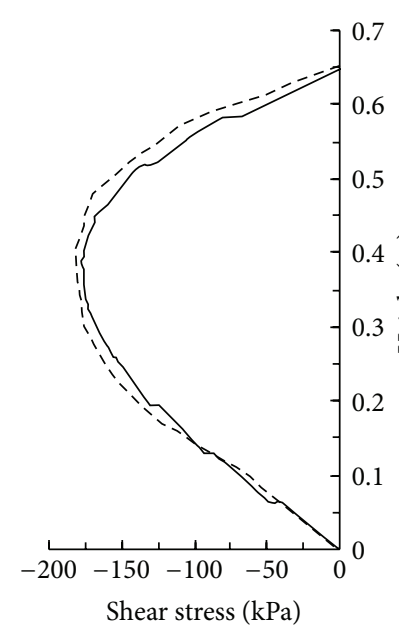

The 2 nd section

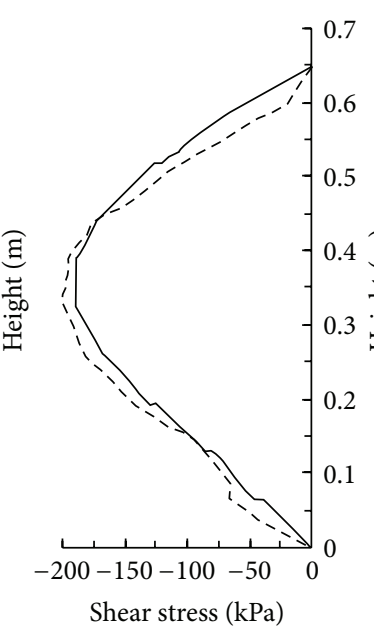

The 3 rd section

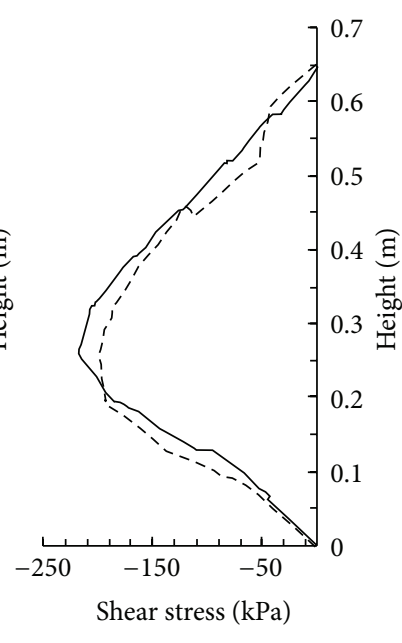

The 4 th section

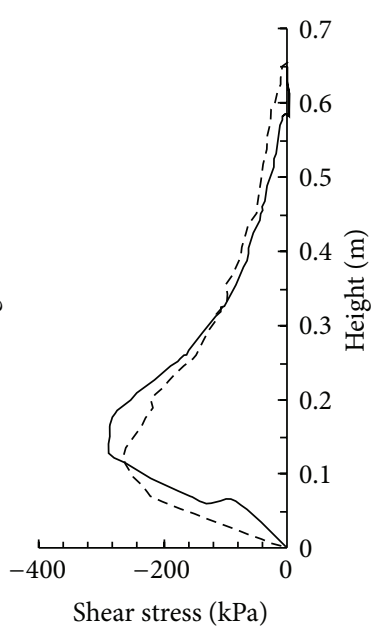

The 5 th section

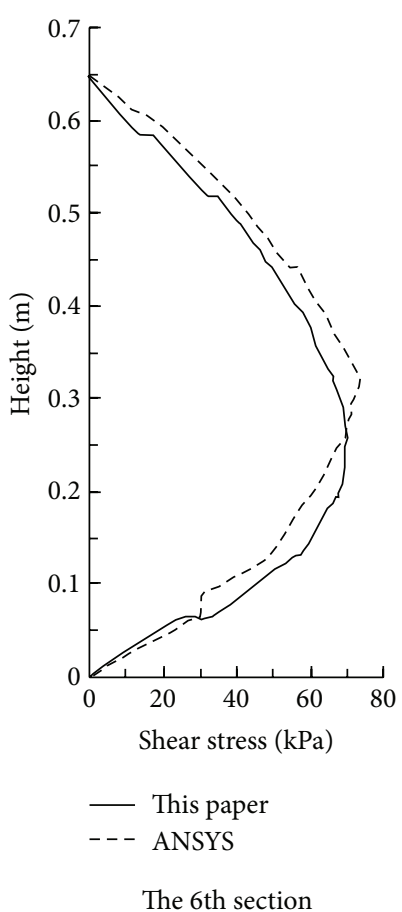

The 6 th section

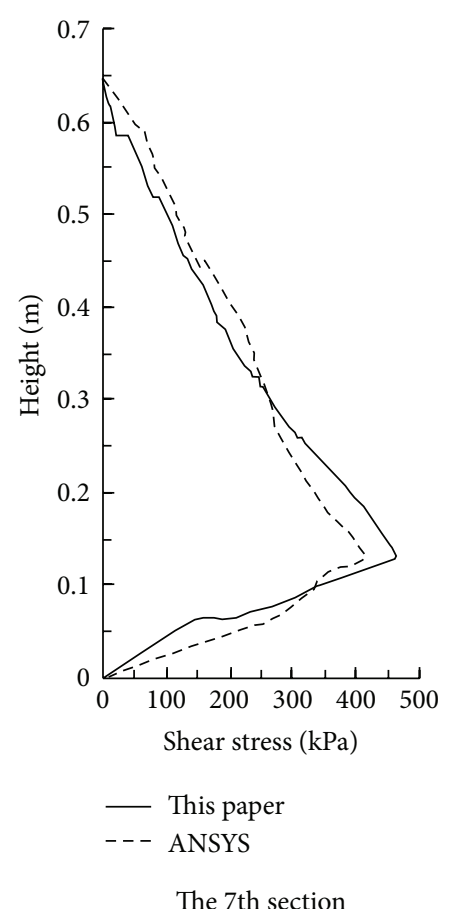

(b)
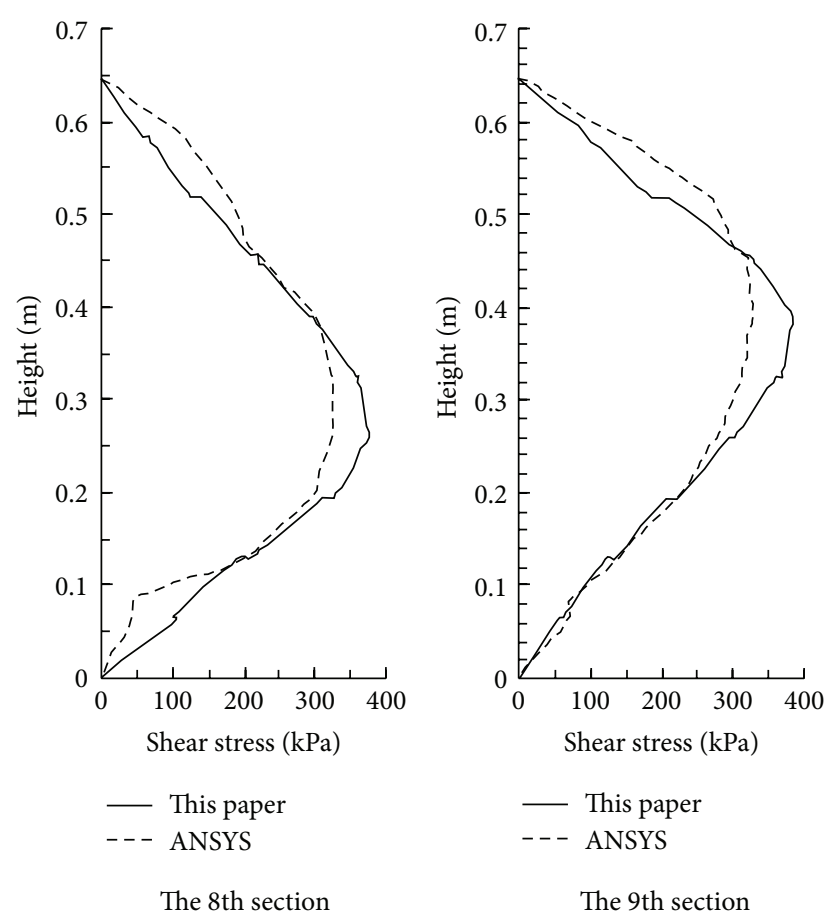

FIgURE 6: (a) The location of the observed cross-section. (b) The shear stress curves along the beam height.

and the only error for ANSYS model and the theoretical model is because of the difference in mesh generation, model simplification, and parameter selection. In the present study, the transverse strain distribution curves are not consistent with the linear relation but the curve relation; the same as the other research studies, which shows that the deep beam no longer matches the plane section assumption [17]. The reason is that there are the shear stress and the normal stress in the 


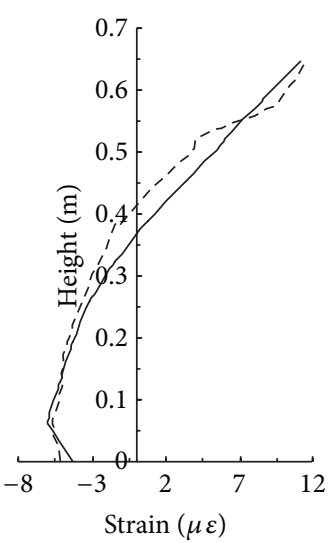

The 2nd section

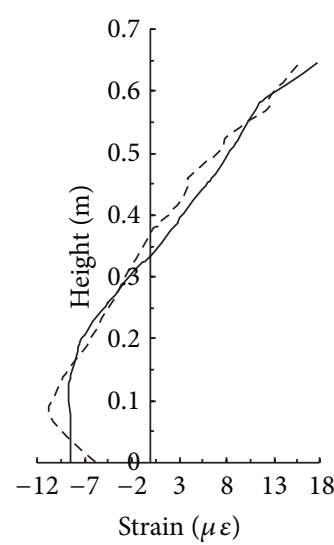

The 3rd section

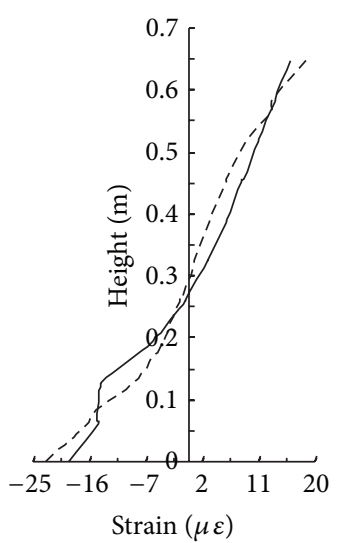

The 4th section

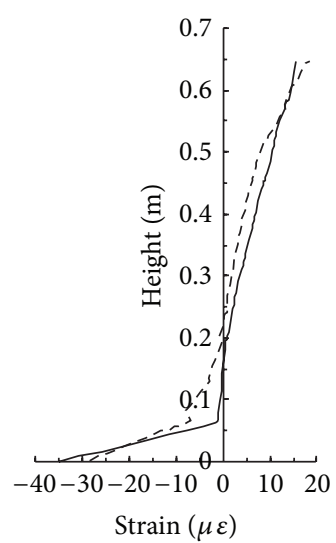

The 5th section

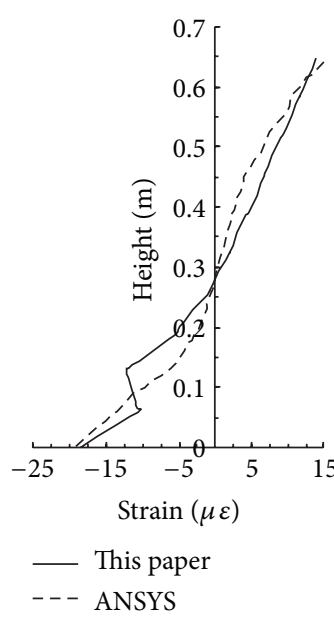

The 6 th section

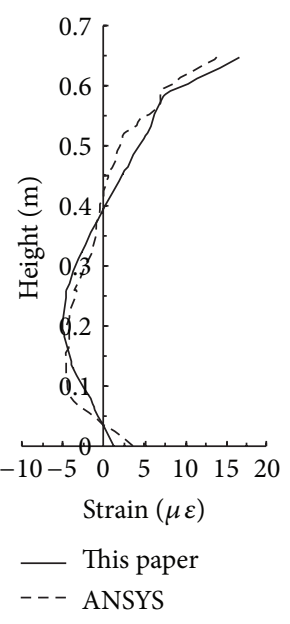

The 7 th section

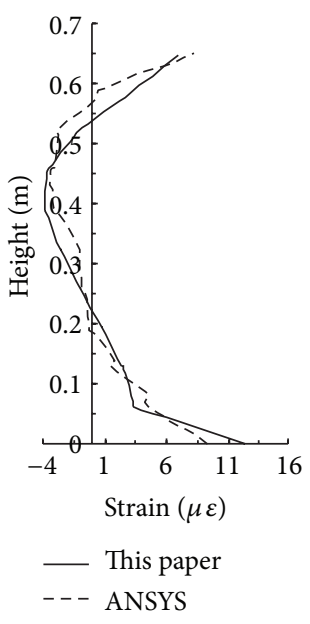

The 8th section

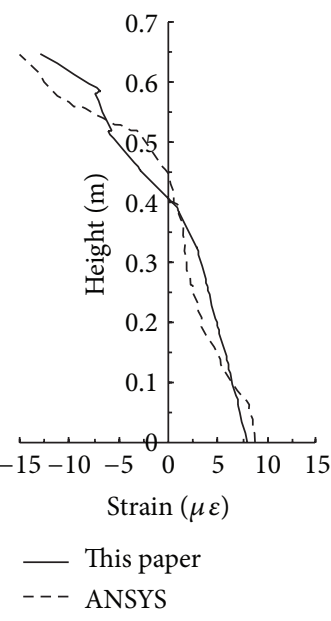

The 9th section

Figure 7: The transverse strain curves along the beam height.

cross-section of the beam, and the shear stress can lead to the cross-section warping while the normal stress can lead to the section in parallel with the neutral layer extrusion.

Figure 8 shows the curve of the transverse strain distribution along with the different beam height $(h=0.65 \mathrm{~m}, h=$ $0.55 \mathrm{~m}, h=0.45 \mathrm{~m}, h=0.35 \mathrm{~m}, h=0.25 \mathrm{~m})$ in Section 2 . With the beam height changes, the transverse strain curve turns to be the linear relation and matches the plane section assumption gradually, that is because the beam belongs to the continuous shallow beam instead of the continuous deep beam with the decrease of the beam height and the plane section assumption can be used again. The pattern in Figure 8 is same to the former research achievements [17] which proved the validity of the calculation model again.

(4) Vertical Compression Deformation Curves of the Different Grounds in the Middle Support Section. Figure 9 shows the vertical compression deformation curves of the different points in the middle support section. When the beam height goes higher, the vertical compression deformations of the different points are bigger in the middle support section and while the beam height is lower, the vertical compression deformations are smaller. With the increase of beam height, the vertical compression deformations impact on the bending deformation of the multispan continuous deep beam increasingly.

\section{Conclusions}

In this paper, we exploited the state space theory to analyze the multispan continuous deep beam and put forward a new way to solve the structure design of the multispan continuous deep beam, which will enlarge the application scope of the state space theory.

The model was established without the plane section assumption and the stress and the displacement assumption, so it is more efficient in the establishment and calculation than ANSYS model; also it has wider application range and higher precision, especially in the calculation of the large composite structure.

This paper reveals that there are the shear stress and the normal stress in the cross-section of the beam; the shear stress can lead to the cross-section warping and the normal stress can lead to the section in parallel with the neutral 

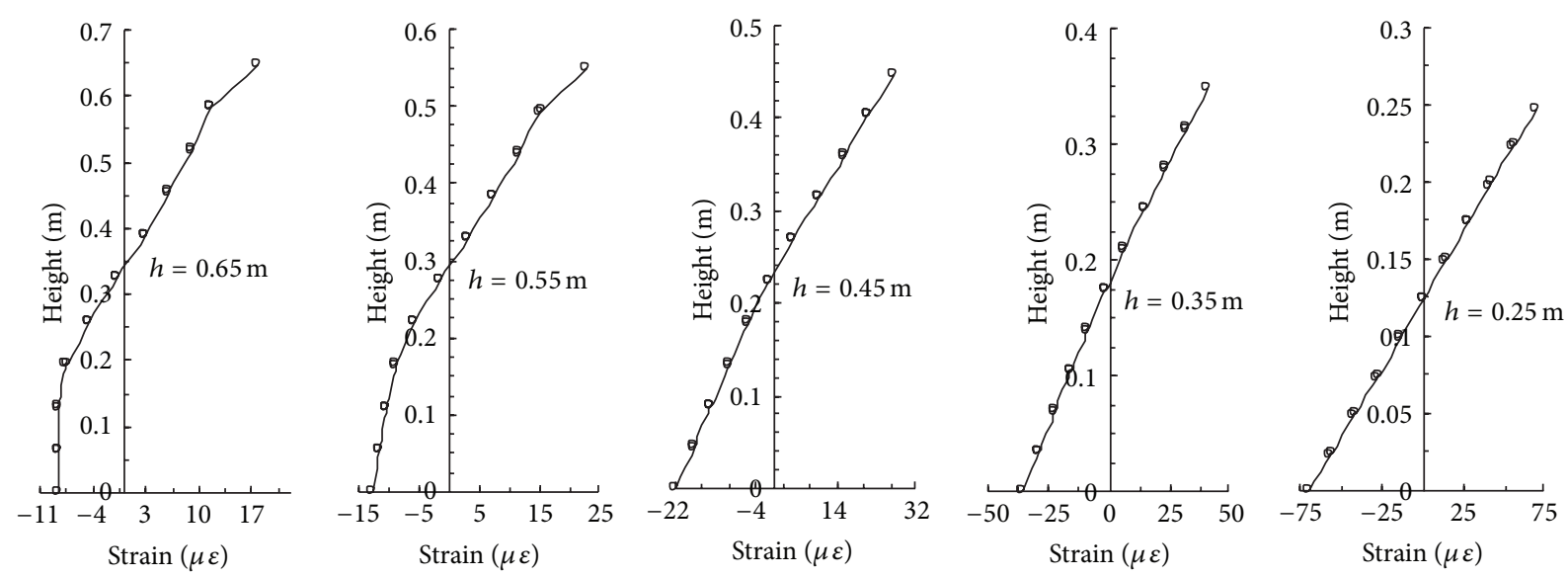

FIGURE 8: The transverse strain curves along the beam height of different beam.
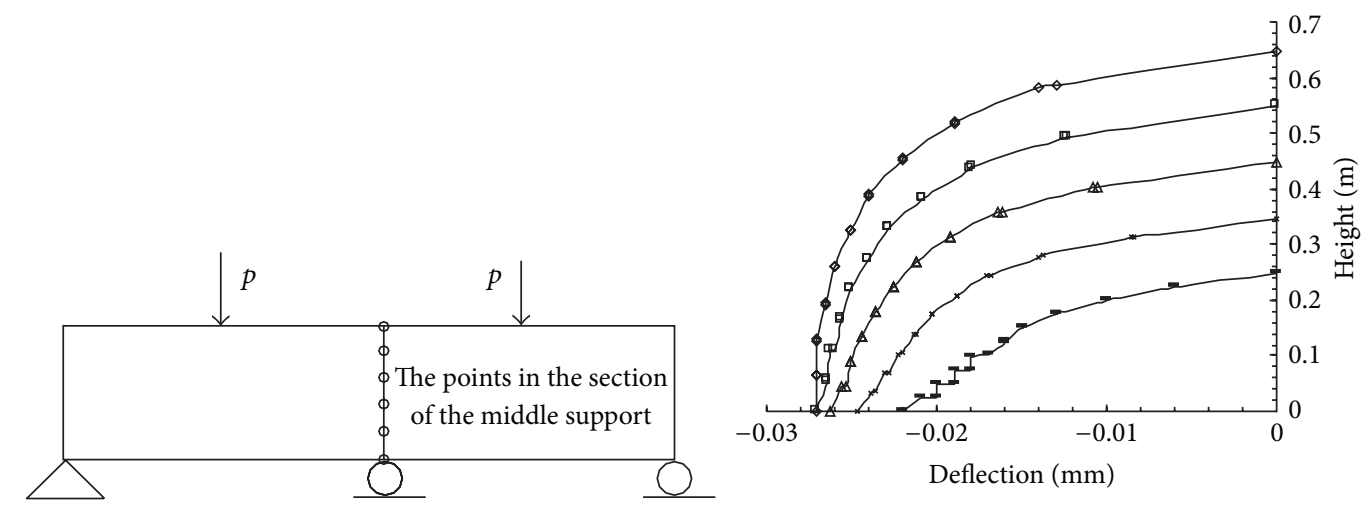

$$
\begin{aligned}
& \rightarrow h=0.65 \mathrm{~m} \quad \rightarrow h=0.35 \mathrm{~m} \\
& \rightarrow h=0.55 \mathrm{~m} \quad-h=0.25 \mathrm{~m} \\
& \triangle h=0.45 \mathrm{~m}
\end{aligned}
$$

Figure 9: The vertical compression deformation curves of the different grounds in the middle support section.

layer extrusion. With the increase of beam height, the vertical compression deformations can impact on the bending deformation of the multispan continuous deep beam increasingly. The calculation solution is consistent with ANSYS solution, and the mechanics pattern revealed by the model is similar to the former research achievements which suggests that the model can be used for practical calculation.

\section{References}

[1] Z.-Z. Wang, J.-Z. Zhu, L. Chen, J.-L. Guo, D.-Y. Tan, and W.-J. Mi, "Stress calculation method for deep beams with shear-bending coupling distortion under concentrated load," Engineering Mechanics, vol. 25, no. 4, pp. 115-120, 2008.

[2] G. R. Cowper, “The shear coefficient in timoshenko's beam theory," Journal of Applied Mechanics, vol. 33, no. 2, pp. 335-340, 1966.

[3] S. P. Timoshenko and J. M. Gere, Strength of Materials, Vannostrand Company, New York, NY, USA, 1972.
[4] R. D. Mindlin, "Influence of Rotary inertia and shear on flexural motions of isotropic, elastic Plates," Journal of Applied Mechanics, vol. 18, pp. 31-38, 1951.

[5] M. Levinson, "A new rectangular beam theory," Journal of Sound and Vibration, vol. 74, no. 1, pp. 81-87, 1981.

[6] M. Levinson, "Further results of a new beam theory," Journal of Sound and Vibration, vol. 77, no. 3, pp. 440-444, 1981.

[7] Y. Gao and M. Z. Wang, "Refined theory of symmetry deformation rectangular beam," Science in China G, vol. 4, pp. 517-522, 2009 (Chinese).

[8] B. Y. Yang, X. T. Wu, and H. P. Li, "Research on the precision of the numerical calculation of the displacement of short or deep beams with shear and bending," Journal of Applied Mechanics, vol. 20, no. 2, pp. 145-146, 2003.

[9] P. L. Mei and D. S. Zeng, "Precise solution of deep beams," Mechanics and Practice, vol. 24, no. 3, pp. 58-60, 2002 (Chinese).

[10] G. F. Wang, "Stress analysis of simply supported deep beams," Journal of Chengdu University of Science and Technology, vol. 70, no. 3, pp. 70-76, 1993 (Chinese). 
[11] D. J. Ding and W. Q. Liu, "Solution of deep beams based on mechanics of bar system," Engineering Mechanics, vol. 10, no. 1, pp. 10-18, 1993 (Chinese).

[12] L. Z. Chen and Z. Z. Li, "Series solution of continuous deep beam under distributed load," Design and Research, vol. 32, no. 9, pp. 30-32, 2005 (Chinese).

[13] Z. Z. Wang and J. D. Sha, "Calculation of normal stress and deflection in transverse bending of main beam in outlet gate," Journal of Hydraulic Engineering, vol. 9, pp. 40-46, 1995 (Chinese).

[14] C. M. Wang, K. Y. Lam, X. Q. He, and S. Chucheepsakul, "Large deflections of an end supported beam subjected to a point load," International Journal of Non-Linear Mechanics, vol. 32, no. 1, pp. 63-72, 1997.

[15] Y.-C. Jiang, X.-F. Hu, and H. Chen, "The series solution of sum function method for simple supported deep beam," Journal of Sichuan University, vol. 38, no. 6, pp. 63-67, 2006 (Chinese).

[16] Z. Z. Wang and L. C. Li, "Critical span-depth ratio of thinwalled steel beam," Mechanics in Engineering, vol. 19, no. 4, pp. 23-24, 1997.

[17] X. Y. Wang, Experimental study and finite element analysis on new steel reinforced concrete beam [Ph.D. dissertation], Central South University, 2007. 


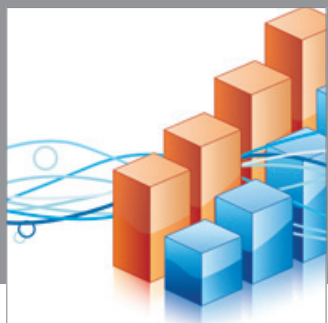

Advances in

Operations Research

mansans

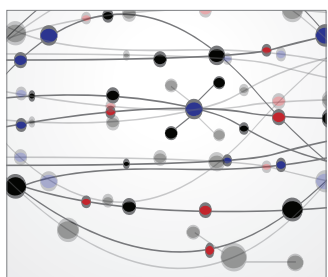

The Scientific World Journal
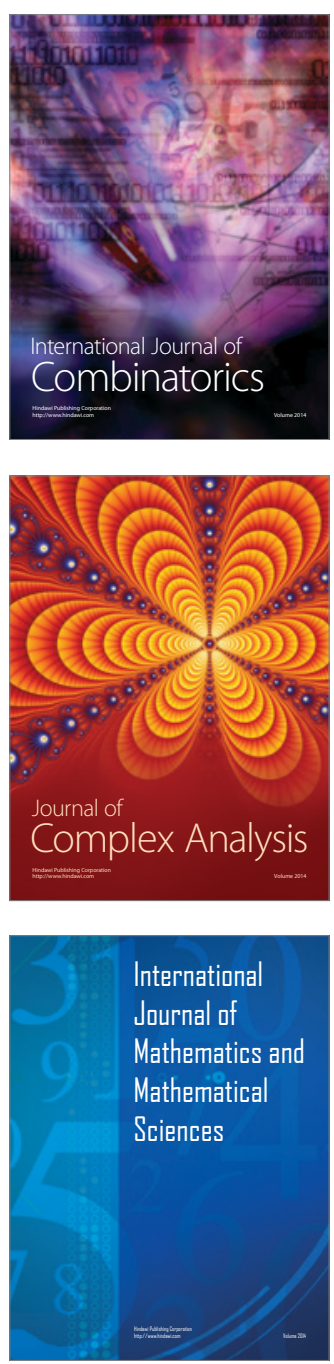
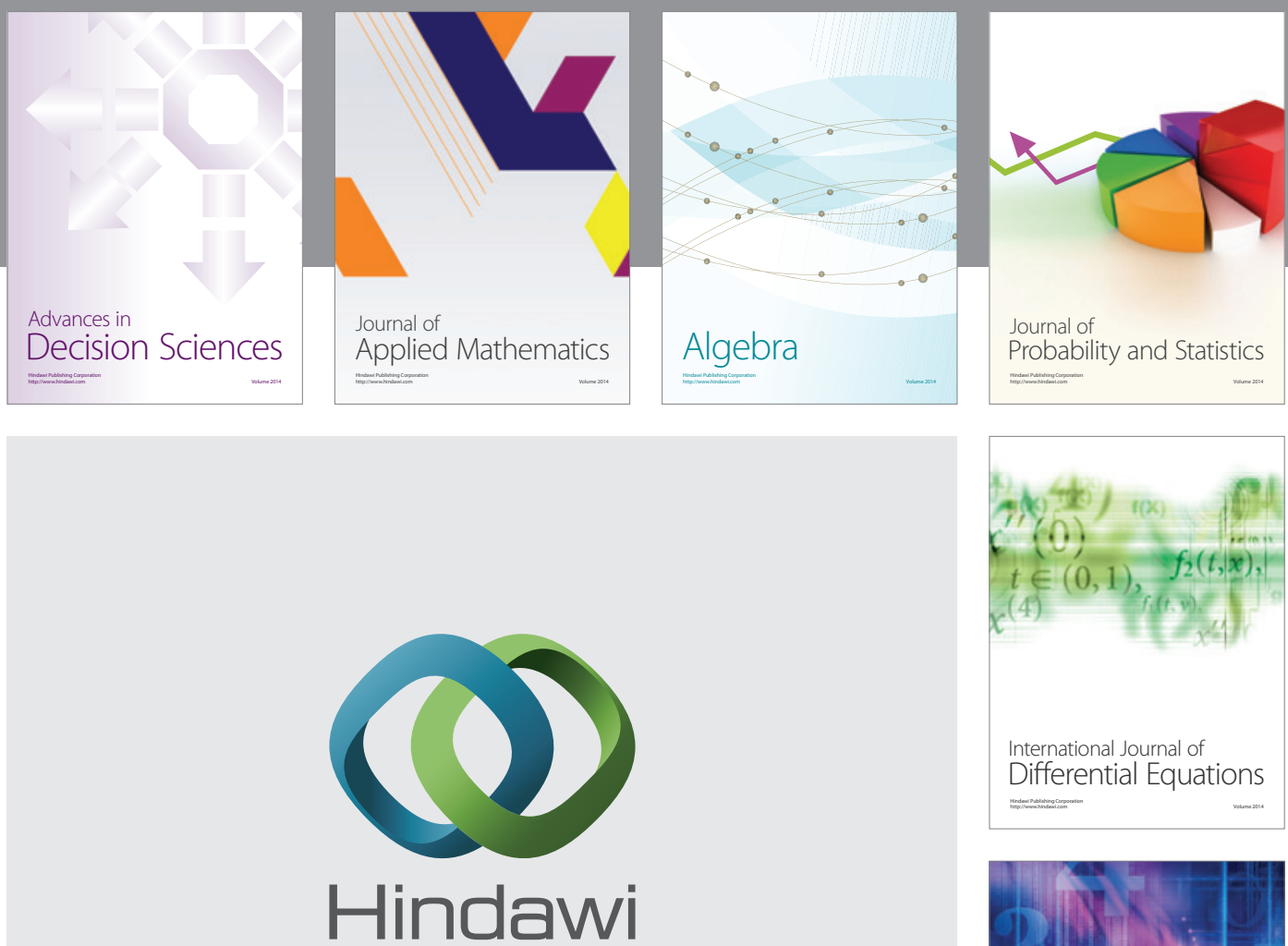

Submit your manuscripts at http://www.hindawi.com
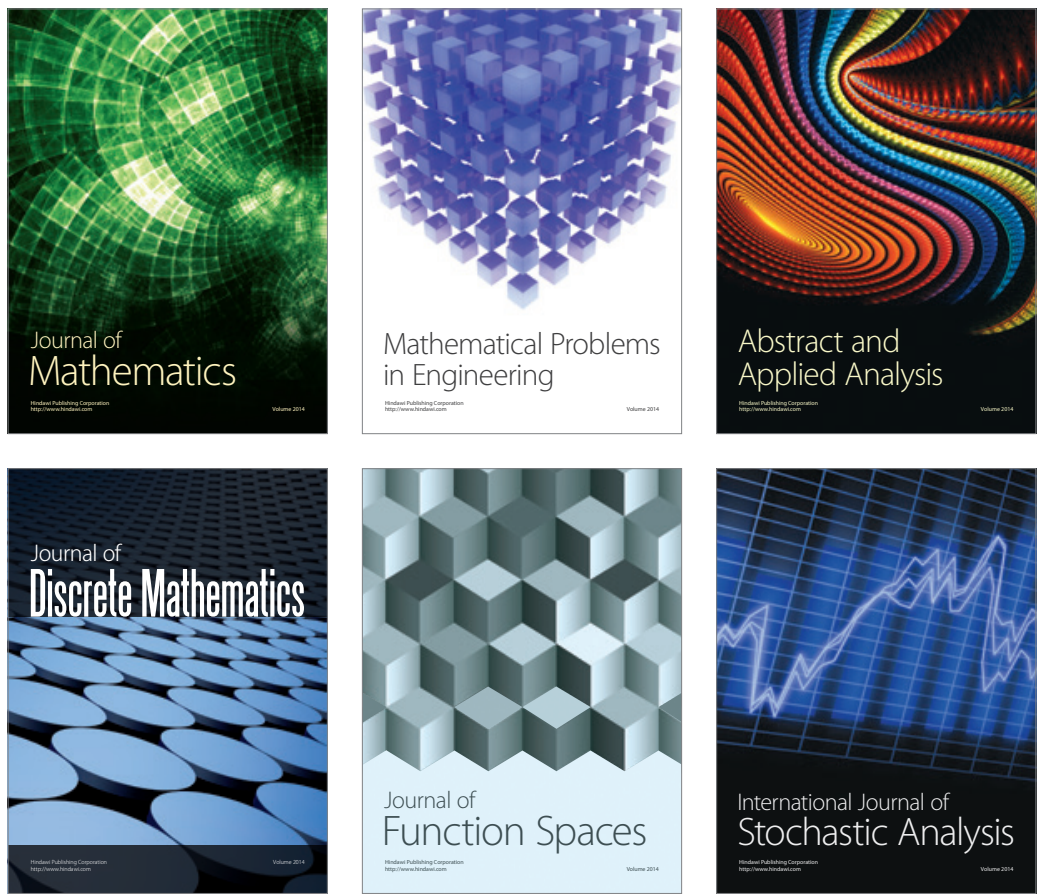

Journal of

Function Spaces

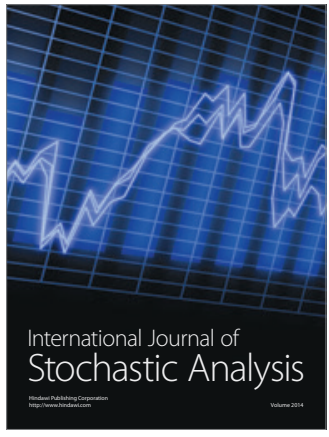

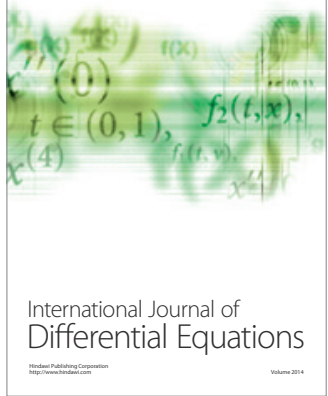
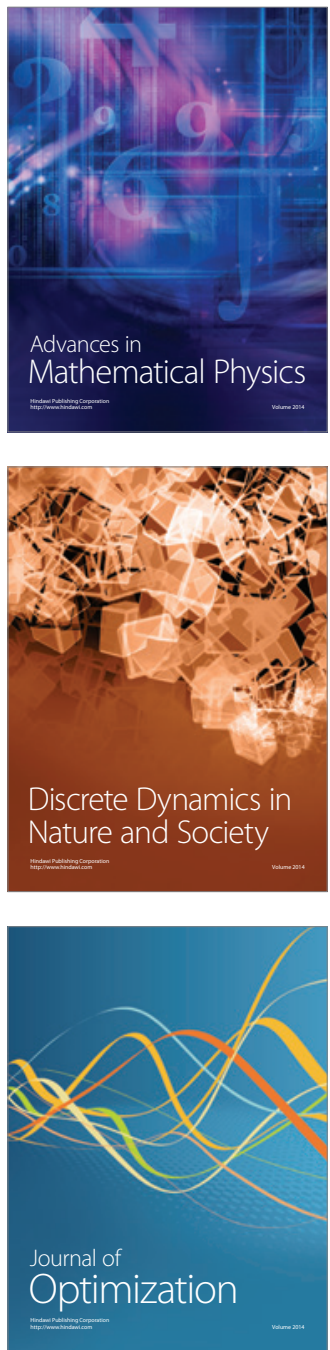